\title{
STATISTICAL PROCESS CONTROL OF ACOUSTIC EMISSION FOR CUTTING TOOL MONITORING
}

\author{
Ali A. Houshmand and Elijah Kannatey-Asibu, JR $\dagger$ \\ Department of Industrial and Operation Engineering and $\dagger$ Department of Mechanical Enginering and \\ Applied Mechanics, The University of Michigan, Ann Arbor, MI 48109, U.S.A.
}

\begin{abstract}
The problem of cutting process monitoring has been investigated in recent years, with encouraging results, using pattern recognition analysis of acoustic emission (AE) signals. The analyses are based on linear discriminant functions, which assume that the observed data (from each class) are independent random samples from multivariate normal distributions with equal covariance matrices. However, in a number of practical situations some (or all) of these assumptions may not necessarily hold, resulting in errors in the analysis.

In this paper, the distributions of AE spectra generated in earlier work are first analysed, and the results indicate departure from the assumptions, although the lack of normality was not too severe. Relaxing the assumption of equality of the covariance matrices, quadratic discriminant function analysis produced improved results for tool wear and chip noise monitoring while degrading tool fracture detection. The latter is due to inadequacy of the amount of data used in training the system. It is expected that increasing the data base would improve the results for all classes.

The analysis until now has focused on reducing the dimensionality of the feature space by eliminating the features with the least discriminatory power. Even though this inevitably reduces the performance of the system, it is a necessary compromise for increased computational speed. To make use of the entire feature set with a reduced matrix rank, a principal component analysis is investigated. The result is a substantial improvement in correct classification of AE signals, even under different cuting conditions.
\end{abstract}

\section{INTRODUCTION}

Automation of metal cutting processes have always been a principal goal of the manufacturing industry. However, the inability to monitor completely the condition of the cutting tool in real time has been a major obstacle to achieving this goal. Tool breakage and tool wear can result in substantial cost through damage to machinery and parts produced, as well as the cost associated with machine downtime.

Much research has recently been done to monitor the conditions of cutting tools in machining processes. In recent years, acoustic emission (AE) has been investigated as an effective sensing technique for machining processes. AE refers to elastic stress waves generated as a result of the rapid release of strain energy within a material due to a rearrangement of its internal structure. It has been applied to a variety of situations including weld flaw detection, fracture and crack propagation in pressure vessels, and mechanical equipment and material property evaluation during tensile testing. AE can be used to obtain direct information about the major activities of metal cutting, including plastic deformation, frictional contact, and fracture of both chip and tool. However, a major problem area has been the development of signal decomposition schemes that can identify and separate the contributions from these sources.

Statistical techniques have been used to develop a methodology for AE signal decomposition. The methods generally used to analyse AE signals corresponding to tool wear and 
tool breakage were based on descriptive statistics, e.g. [1-4]. Kannatey-Asibu and Dornfeld [5] list several statistical methods which have been used in the past to analyse AE signals. Among them are: "count and count rate" (which is a record of signals whose amplitude exceed a pre-set threshold voltage), "amplitude distribution analysis" (which gives an indication of the number of signals whose amplitude fall within a predefined range), and "frequency spectrum" (which shows the contribution of each frequency component to the total power). Also, Kannatey-Asibu and Dornfeld [3] carried out experiments and analysed the data by assuming that the distribution of the rms value of $\mathrm{AE}$ signals follows a beta-distribution with some parameters. They found that the skewness and the kurtosis which are functions of the parameters of the assumed beta-distribution, were sensitive to progressive tool wear.

Kannatey-Asibu [6] proposed the use of linear discriminant function analysis as a technique for $\mathrm{AE}$ signal decomposition, in order to identify sources of $\mathrm{AE}$ signals in metal cutting processes. Following this work, others have studied the use of this technique to monitor the condition of cutting tools in metal cutting processes. See, for example [7,8]. Emel and Kannatey-Asibu [9] conducted controlled experiments on a lathe under three different cutting conditions, and obtained data for four different classes, viz, chip noise, tool fracture, sharp tool, and worn tool. The data was used to develop linear discriminant functions for classifying future incoming signals. They concluded that the results indicate an $84-94 \%$ reliability for detecting tool failure of any type.

Although classification seems to be a good statistical technique for signal decomposition, much work needs to be done before one can use it to analyse AE signals for on-line cutting tool monitoring. This paper discusses the use of appropriate statistical techniques for analysis of frequency domain AE signals to monitor cutting tools. It will be shown, using the experimental data of Emel and Kannatey-Asibu [9], that substantial improvement over the results to date is achieved by the use of these techniques. The next section gives a general statement of the problem that we are investigating.

\section{PROBLEM STATEMENT}

Consider a process that can be in one of $s(s \geqslant 2)$ mutually exclusive states. One of these states is defined as in control, and the rest are defined as out of control. For example, in a metal cutting process the in control state corresponds to a sharp and healthy cutting tool, whereas the out of control states correspond to a worn tool, fractured tool, or both. Suppose that the process can be monitored, at some regular intervals, through measurements of $\mathbf{k}$-dimensional vectors of observations (attributes). In the above metal cutting example, these vectors of observations can each be a $\mathrm{k}$-dimensional vector of spectral power components of AE signals, generated at regular intervals from the cutting process. Suppose that before actual monitoring of the process begins, controlled experiments have been conducted, where the process has been set at each possible state $i(i=1,2, \ldots, s)$, and $n_{i}$ vectors of attributes (we refer to these vectors of attributes as the training sets) have been obtained from each of these states. For $i=1,2, \ldots, s$ states, let us denote these vectors of attributes by $\mathbf{x}_{1}^{i}, \mathbf{x}_{2}^{i}, \ldots, \mathbf{x}_{n_{i}}^{i}$. The superscript $i$ specifies that an observation belongs to state $i$, and the subscripts $1,2, \ldots, n_{i}$ specify the order (time interval) in which the observations have been taken. For example, in the cutting process, $i=2$ may denote a worn tool. Then $x_{1}^{i}, x_{2}^{2}, \ldots, x_{20}^{2}$ denote 20 vectors (e.g. $k$-dimensional spectral power components of AE signals) of observations which have been taken at regular intervals from a controlled experiment where a worn tool has been used for machining.

Now let us assume that the actual cutting process starts in control, i.e., with a sharp and "healthy" tool. As cutting continues, the tool experiences wear. At some point in the 
process, we observe a single $k$-dimensional vector of attributes, $\mathbf{x}^{\prime}=\left(x_{1}, x_{2}, \ldots, x_{k}\right)$. If it is determined that $\mathbf{x}$ is generated by an out of control state, i.e., worn or broken tool, then the process will be stopped for inspection and corrective action taken, otherwise it will continue. The problem we will be concerned with is to determine which one of the $\mathbf{s}$ mutually exclusive states has generated $\mathbf{x}$, and whether to stop the process for inspection and correction.

\section{BACKGROUND}

The problem of classification may be considered as a "statistical decision function" problem, where we have a number of hypotheses each stating that the subject under investigation belongs to a particular distribution. We must accept one of these hypotheses and reject the others. The classification problem was first studied by Fisher [10], followed by Smith [11]. It has since been studied by many authors, see, for example [12-19]. In this section, we briefly discuss the classification functions as well as the principal components analysis as the basis for our data analysis.

\subsection{DISCRIMINANT FUNCTIONS}

Theorem. Suppose $\mathbf{x}$ is an observation from one of the $s$ multivariate populations $\Pi_{i}$ with density $f_{i}\left(\mathbf{x} \mid \boldsymbol{\Omega}_{i}\right)$, where $\boldsymbol{\Omega}_{i}$ represents the known matrix of the parameters of the distribution. If $p_{i}$ is the a priori probability of $\mathbf{x}$ belonging to $\Pi_{i}$, and if $C_{i j}$ is the cost of misclassifying $\mathrm{x}$ as belonging to $\Pi_{i}$ when it actually belongs to $\Pi_{j}$, then the regions of classification $R_{1}, R_{2}, \ldots, R_{s}$ that minimise the expected cost of misclassification are defined by assigning $\mathbf{x}$ to $R_{r}$ if

$$
\sum_{\substack{i=1 \\(i \neq r)}}^{s} p_{i} C_{r i} f_{i}\left(\mathbf{x} \mid \mathbf{\Omega}_{i}\right)<\sum_{\substack{i=1 \\(i \neq j)}}^{s} p_{i} C_{j i} f_{i}\left(\mathbf{x} \mid \mathbf{\Omega}_{i}\right) \quad \text { for all } j=1,2, \ldots, s ; j \neq r
$$

For $s=2$, the above theorem states: classify $\mathbf{x}$ into $R_{1}$ if

$$
p_{2} C_{12} f_{2}\left(\mathbf{x} \mid \mathbf{\Omega}_{2}\right)<p_{1} C_{21} f_{1}\left(\mathbf{x} \mid \mathbf{\Omega}_{1}\right) .
$$

Now suppose that $\Pi_{i}$ is a multivariate normal distribution with known mean vector $\boldsymbol{\mu}_{i}$, and covariance matrix $\Sigma_{i},(i=1,2)$. By the above theorem, in order to minimise the expected cost of misclassification, we classify $\mathbf{x}$ into $\Pi_{1}$ if:

$$
\frac{\left|\Sigma_{1}\right|^{-1 / 2} \exp \left\{-\frac{1}{2}\left(\mathbf{x}-\boldsymbol{\mu}_{1}\right)^{\prime} \Sigma_{1}^{-1}\left(\mathbf{x}-\boldsymbol{\mu}_{1}\right)\right\}}{\left|\Sigma_{2}\right|^{-1 / 2} \exp \left\{-\frac{1}{2}\left(\mathbf{x}-\mu_{2}\right)^{\prime} \Sigma_{2}^{-1}\left(\mathbf{x}-\mu_{2}\right)\right\}} \geqslant \frac{p_{2} C_{12}}{p_{1} C_{21}}
$$

Taking the natural logarithm (ln) of both sides and simplifying gives

$$
\left[\left(\mathbf{x}-\mu_{2}\right)^{\prime} \Sigma_{2}^{-1}\left(\mathbf{x}-\mu_{2}\right)-\left(\mathbf{x}-\mu_{1}\right)^{\prime} \Sigma_{1}^{-1}\left(\mathbf{x}-\mu_{1}\right)\right] \geqslant 2 \ln \left[\frac{\left|\Sigma_{1}\right|^{1 / 2} p_{2} C_{12}}{\left|\Sigma_{2}\right|^{1 / 2} p_{1} C_{21}}\right] .
$$

Equation (3.4) is the quadratic discriminant function of $\mathbf{x}$. If $\Sigma_{1}=\Sigma_{2}, p_{1}=p_{2}$, and $C_{12}=C_{21}$, then (3.4) reduces to the simple linear discriminant function of $\mathbf{x}$ given by:

$$
\mathbf{x}^{\prime} \boldsymbol{\Sigma}^{-1}\left(\boldsymbol{\mu}_{1}-\boldsymbol{\mu}_{2}\right)-\frac{1}{2}\left(\boldsymbol{\mu}_{1}+\boldsymbol{\mu}_{2}\right)^{\prime} \boldsymbol{\Sigma}^{-1}\left(\boldsymbol{\mu}_{1}-\boldsymbol{\mu}_{2}\right) \geqslant 0 \text {. }
$$

If there are more than two populations $(s>2)$, and their misclassification costs are equal, then the rule for classifying $x$ into one of these populations is to calculate the a posteriori probability for each population and assign $\mathbf{x}$ to that population with the largest a posteriori probability. In the case of unequal normal population coveraince matrices, the a posteriori probability for population i can be obtained by exponentiating 
the expression

$$
-\frac{1}{2} \mathbf{x}^{\prime} \Sigma_{i}^{-1} \mathbf{x}+\mathbf{x}^{\prime} \Sigma_{i}^{-1} \boldsymbol{\mu}_{i}-\frac{1}{2} \mu_{i}^{\prime} \Sigma_{i}^{-1} \boldsymbol{\mu}_{i}+\ln p_{i}-\ln \left|\Sigma_{i}\right|^{1 / 2}
$$

for each $i$. If the covariance matrices are equal the a posteriori probability for the population i can correspondingly be obtained from

$$
\mathbf{x}^{\prime} \Sigma^{-1} \boldsymbol{\mu}_{i}+\ln p_{i}-{ }_{2}^{1} \boldsymbol{\mu}_{i}^{\prime} \Sigma^{-1} \boldsymbol{\mu}_{i}
$$

which is the linear discriminant function of $\mathbf{x}$.

The results described above are based on the assumption that the population parameters are all known. However, in practice these are seldom known, and therefore must be estimated from data. This means that the above results are valid if large samples are available to give reliable estimators.

\subsection{PRINCIPAL COMPONENT ANALYSIS}

Suppose we have a k-dimensional random vector $\mathbf{X}^{\prime}=\left(X_{1}, X_{2}, \ldots, X_{k}\right)$ having a multivariate (not necessarily normal) distribution with mean vector $\mu$ and covariance matrix $\Sigma$. We can find linear combinations $Y_{1}, Y_{2}, \ldots, Y_{r}$ of $X_{1}, X_{2}, \ldots, X_{k}(r<k)$ which convey approximately the same amount of variance as expressed by the original variables. The variables $Y_{1}, Y_{2}, \ldots, Y_{r}$ are called the first $r$ principal components of the dependence structure among $X_{1}, X_{2}, \ldots, X_{k}$, and are evaluated as follows:

Let

$$
Y_{i}=\sum_{j=1}^{k} \alpha_{i j} X_{j} \text { for } i=1,2, \ldots, r
$$

Then

$$
\operatorname{maximise}_{\left\{\alpha_{1 k}\right\}} \operatorname{var}\left(Y_{i}\right)=\operatorname{var}\left(\sum_{j=1}^{k} \alpha_{1 j} X_{j}\right)
$$

subject to the constraint

$$
\sum_{j=1}^{k} \alpha_{1 j}^{2}=1
$$

This gives $\boldsymbol{\alpha}_{1}^{\prime}=\left(\alpha_{11}, \alpha_{12}, \ldots, \alpha_{1 k}\right)$ as the set of weights which maximise $\operatorname{var}\left(Y_{1}\right) . \alpha_{1}$ is the eigenvector corresponding to the largest eigenvalue of $\Sigma$ which is equal to $\operatorname{var}\left(Y_{1}\right)$. Next we solve

$$
\operatorname{maximise} e_{\left\{\alpha_{2 k}\right\}} \operatorname{var}\left(Y_{2}\right)=\operatorname{var}\left(\sum_{j=1}^{k} \alpha_{2 j} X_{j}\right)
$$

subject to the constraint

$$
\sum_{j=1}^{k} \alpha_{2 j}^{2}=1 \text { and } \operatorname{covar}\left(Y_{1}, Y_{2}\right)=0
$$

This gives $\boldsymbol{\alpha}_{2}^{\prime}=\left(\alpha_{21}, \alpha_{22}, \ldots, \alpha_{2 k}\right)$ as the set of weights which maximise $\operatorname{var}\left(Y_{2}\right) . \boldsymbol{\alpha}_{2}$ is the eigenvector corresponding to the second largest eigenvalue of $\Sigma$ which is equal to $\operatorname{var}\left(Y_{2}\right)$. After $Y_{1}, Y_{2}, \ldots, Y_{r-1}$, have been obtained, we solve

$$
\operatorname{maximise} e_{\left\{\alpha_{r k}\right\}} \operatorname{var}\left(Y_{r}\right)=\operatorname{var}\left(\sum_{j=1}^{k} \alpha_{r j} X_{j}\right)
$$


subject to the constraint

$$
\sum_{j=1}^{k} \alpha_{r j}^{2}=1
$$

and $\operatorname{covar}\left(Y_{m}, Y_{r}\right)=0(m=1,2, \ldots, r-1)$.

This gives $\alpha_{1}^{\prime}=\left(\alpha_{11}, \alpha_{12}, \ldots, \alpha_{1 k}\right)$ as the set of weights which maximise $\operatorname{var}\left(Y_{1}\right) . \alpha_{1}$ is the eigenvector corresponding to the $r$-th largest eigenvalue of $\Sigma$ which is equal to $\operatorname{var}\left(Y_{r}\right)$. Therefore, the principal component analysis rotates the axes of $X_{1}, X_{2}, \ldots, X_{k}$ to obtain the new orthogonal axes $Y_{1}, Y_{2}, \ldots, Y_{r}$ which account for a large portion of the total variance of the $X_{i} s$.

\section{RESULTS AND DISCUSSION}

In this section, we present and discuss the result of our analysis, but first a brief description on how the data [9] were obtained.

Controlled experiments were conducted on a lathe machine under three sets of cutting conditions, which resulted in three sets of data. We refer to these three sets of data as "set 1", "set 2", and "set 3". The cutting conditions corresponding to data sets 1 and 2 are described in Table 1 of Emel and Kannatey-Asibu [9] (they refer to sets 1 and 2 as tests 11 and 13 respectively). Below, we briefly describe how the frequency domain $\mathrm{AE}$ signals were obtained for set 1 . Throughout, we use set 1 to report our findings, and use the other two sets for confirmation.

For each of the four possible states (tool fracture, chip noise, sharp tool, and worn tool), separate recordings of time domain AE signals were made. For example, for the tool fracture state, 29 separate experiments were conducted where each time the tool was deliberately fractured during the machining process and in each case the corresponding AE signals were recorded. One-millisecond time portions of each of these signals were then sampled, corresponding to 4096 data points. The time domain data were then transformed to the frequency domain using the fast Fourier transform (FFT). This resulted in 2048 data points in the frequency range of $1-1000 \mathrm{kHz}$. The sample means of every 40 data points were then calculated to represent 51 (4048 divided by 40 ) features each with a $20 \mathrm{kHz}$ frequency range. The first five features were then discarded due to the low signal-to-noise ratio, in essence filtering off the lower $100 \mathrm{kHz}$ frequencies. This resulted in 46-dimensional vector of features (variables). These 46 power spectral components were further normalised with respect to the total power of the spectrum, using the expression

$$
X_{k}=10 \log \left(\frac{Z_{k}}{\sum_{k=1}^{46} Z_{k}}\right) \text { for } k=1,2, \ldots, 46,
$$

where $Z_{k}$ represents the contribution of feature $k$. This makes the power components invariant to the absolute energy. The end results were 29 independent vectors, each consisting of 46 power components.

For the sharp and worn tool states, separate tests were conducted where sharp and worn tools were used, respectively. In recording continuous AE signals generated from these experiments, transient signals due to chip breakage were also periodically recorded. Chip noise signals were thus obtained from the same tests conducted for sharp and worn tools. For each of these tests, a total of 20 samples (46-dimensional vectors generated in exactly the same way as above) were obtained. Also, from each experiment, up to 20 chip noise samples were obtained. The tests with sharp and worn tools were repeated 
four times each, so a total of 80 vectors of observations were obtained for each of sharp and worn tool states, and a total of 74 vectors of observations were obtained for the chip noise.

Let us assume now that the data from each state are independent random samples from multivariate normal distributions with unknown parameters, and that the sample sizes are large enough so that good estimates of the parameters of these distributions are possible. Furthermore, assume that the population covariance matrices are equal (even though the test for equality of these matrices revealed that they are not). Substituting the appropriate estimates for the parameters in expression (3.7), and using the forward stepwise procedure described in Appendix A, we obtained the linear discriminant functions of data set 1 for the four states (tool fracture, chip noise, sharp tool, and worn tool). We assumed that the a priori probability of an observation belonging to state $i, p_{i}$, as well as the misclassification costs, $c_{i j}$, are the same for all $i$ and $j$. Also, we develop discriminant functions for all four states in order to perform simultaneous classification. This will give results comparable to those in Table 4 of Emel and Kannatey-Asibu [9]. The stepwise procedure selected 14 features (variables) as the most discriminatory features. These features, together with their corresponding frequency bands, are given in Table 1.

Table 2 gives the number of the vectors classified into each state, and the percentage of correct classification which are represented by the boldface numbers along the diagonal. The percentage of correct classifications for the chip noise and the tool fracture states is reasonable but that of the sharp and the worn tool states is very poor. The first possible remedy is to test for the equality of the covariance matrices to see if the quadratic discriminant functions are more appropriate. The percentage of correct classifications in Table 2 can be compared with those obtained by Emel and Kannatey-Asibu [9], shown in Table 3. They used 20 features which were selected by ranking the $F$ statistics corresponding to one-way Anova (see, for example [20]) and selecting the first 20. This feature selection was based on the assumption that the 46 features (variables) were independent, which is not necessarily the case, as illustrated by the data in Table 4 which gives the Pearson correlation coefficients between each pair of eight arbitrarily selected

TABLE 1

The list of 14 features, selected by stepwise discriminant analysis, and their corresponding frequencies

\begin{tabular}{cc}
\hline Feature & Frequency $(\mathrm{kHz})$ \\
\hline 3 & 140 \\
4 & 160 \\
7 & 220 \\
8 & 240 \\
9 & 260 \\
10 & 280 \\
12 & 320 \\
15 & 380 \\
16 & 400 \\
34 & 760 \\
38 & 840 \\
39 & 860 \\
44 & 960 \\
46 & 1000 \\
\hline
\end{tabular}


TABLE 2

The results of $L D$ analysis of the 14 features selected by stepwise procedure. The top entries are number of vectors classified into a population. The bold entries are percentage correct classification

\begin{tabular}{lrrrr}
\hline & \multicolumn{4}{c}{ Classified population } \\
\cline { 2 - 5 } True population & Chip noise & Tool fracture & Sharp tool & Worn tool \\
\hline Chip noise & 67 & 4 & 0 & 3 \\
Tool fracture & 90 & 27 & 0 & 0 \\
Sharp tool & 2 & 93 & 66 & 14 \\
Worn tool & 0 & 0 & $\mathbf{8 2}$ & 55 \\
& 2 & 0 & 23 & 69 \\
\hline
\end{tabular}

\section{TABLE 3}

The results of the linear discriminant analysis of Emel and Kannatey-Asibu [9] for data set 1 (Table 4 in their paper)

\begin{tabular}{lccccc}
\hline & & \multicolumn{4}{c}{ State } \\
\cline { 3 - 6 } & & Chip noise & Tool fracture & Sharp tool & Worn tool \\
\hline $\begin{array}{l}\text { Percentage } \\
\text { classification }\end{array}$ & correct & 84 & 85 & 75 & 61 \\
\hline
\end{tabular}

features in each state. This means that the inclusion of a given feature in the discriminant function may very well depend on the inclusion or exclusion of some other features. This fact has been taken into account in our feature selection procedure (see Appendix $A$ for discussion on how to account for this correlation structure in feature selection). The correlations between each pair of the remaining 38 features were similar to those in Table 4. The four values in each box represent the correlations between the feature specified in the row and the feature specified in the column for each of the four states. For example, the correlation between feature 8 and 7 is 0.248 for the chip noise, 0.34 for the fracture, 0.539 for the sharp tool, and 0.732 for the worn tool state. Most of these correlations are highly significant, which can be compared with the threshold values corresponding to $95 \%$ level of significance, given at the bottom of the table.

The test for equality of population covariance matrices (see, for example [17] for the derivation of the test statistics) was rejected at any level of significance less than 0.001 , so expression (3.6) was used to obtain the quadratic discriminant functions for data set 1. Table 5 gives the number of vectors classified into each state and the percentages of correct classification along the diagonal. As expected, the quadratic procedure performs better overall. However, for the tool fracture state, the percentage of correct classifications drops from 93 to 79 . This is clearly due to the small sample size (29) in this state (Foley [21] suggests that there should be at least four times as many samples as there are features in order to obtain reliable discriminant functions). Also, the covariance matrices must 
TABLE 4

Pearson correlation coefficients $\rho\left(\rho=\operatorname{covar}\left(X_{i}, X_{j}\right) /\left(\operatorname{SQRT}\left(\operatorname{var}\left(X_{i}\right) \cdot \operatorname{var}\left(X_{j}\right)\right), i \neq j\right)\right.$ between the indicated features

\begin{tabular}{|c|c|c|c|c|c|c|c|c|}
\hline Feature & State & $\mathrm{Fr}_{3}$ & $\mathrm{Fr}_{4}$ & $\mathrm{Fr}_{7}$ & $\mathrm{Fr}_{8}$ & $\mathrm{Fr}_{9}$ & $\mathrm{Fr}_{10}$ & $\mathrm{Fr}_{12}$ \\
\hline $\mathrm{Fr}_{4}$ & $\begin{array}{l}\text { CN } \\
\text { FR } \\
\text { SH } \\
\text { WR }\end{array}$ & $\begin{array}{l}0.304 \\
0.405 \\
0.726 \\
0.667\end{array}$ & & & & & & \\
\hline $\mathrm{Fr}_{7}$ & $\begin{array}{l}\text { CN } \\
\text { FR } \\
\text { SH } \\
\text { WR }\end{array}$ & $\begin{array}{r}0.289 \\
-0.621 \\
0.609 \\
0.448\end{array}$ & $\begin{array}{r}0.253 \\
-0.219 \\
0.645 \\
0.638\end{array}$ & & & & & \\
\hline $\mathrm{Fr}_{8}$ & $\begin{array}{l}\mathrm{CN} \\
\mathrm{FR} \\
\mathrm{SH} \\
\mathrm{WR}\end{array}$ & $\begin{array}{r}-0.121 \\
-0.080 \\
0.276 \\
0.356\end{array}$ & $\begin{array}{l}0.080 \\
0.342 \\
0.338 \\
0.449\end{array}$ & $\begin{array}{l}0.248 \\
0.340 \\
0.539 \\
0.732\end{array}$ & & & & \\
\hline $\mathrm{Fr}_{9}$ & $\begin{array}{l}\text { CN } \\
\text { FR } \\
\text { SH } \\
\text { WR }\end{array}$ & $\begin{array}{r}-0 \cdot 208 \\
-0.158 \\
0.106 \\
0.331\end{array}$ & $\begin{array}{r}-0.156 \\
0.311 \\
0.058 \\
0.361\end{array}$ & $\begin{array}{r}-0.156 \\
0.260 \\
0.325 \\
0.684\end{array}$ & $\begin{array}{l}0.389 \\
0.724 \\
0.392 \\
0.717\end{array}$ & & & \\
\hline $\mathrm{Fr}_{10}$ & $\begin{array}{l}\text { CN } \\
\text { FR } \\
\text { SH } \\
\text { WR }\end{array}$ & $\begin{array}{r}0.067 \\
0.155 \\
-0.281 \\
0.134\end{array}$ & $\begin{array}{r}0.154 \\
0.692 \\
-0.266 \\
0.252\end{array}$ & $\begin{array}{r}0.277 \\
0.066 \\
-0.115 \\
0.604\end{array}$ & $\begin{array}{l}0.283 \\
0.550 \\
0.196 \\
0.677\end{array}$ & $\begin{array}{l}0.218 \\
0.541 \\
0.447 \\
0.624\end{array}$ & & \\
\hline $\mathrm{Fr}_{12}$ & $\begin{array}{l}\text { CN } \\
\text { FR } \\
\text { SH } \\
\text { WR }\end{array}$ & $\begin{array}{l}-0.252 \\
-0.547 \\
-0.633 \\
-0.269\end{array}$ & $\begin{array}{l}-0.028 \\
-0.475 \\
-0.534 \\
-0.182\end{array}$ & $\begin{array}{r}0.133 \\
0.187 \\
-0.432 \\
0.145\end{array}$ & $\begin{array}{r}0.239 \\
-0.071 \\
-0.102 \\
0.316\end{array}$ & $\begin{array}{r}0.136 \\
-0.041 \\
0.243 \\
0.436\end{array}$ & $\begin{array}{r}0.169 \\
-0.468 \\
0.542 \\
0.429\end{array}$ & \\
\hline $\mathrm{Fr}_{15}$ & $\begin{array}{l}\text { CN } \\
\text { FR } \\
\text { SH } \\
\text { WR }\end{array}$ & $\begin{array}{r}-0.296 \\
0.054 \\
-0.802 \\
-0.713\end{array}$ & $\begin{array}{l}-0.523 \\
-0.207 \\
-0.760 \\
-0.699\end{array}$ & $\begin{array}{l}-0.560 \\
-0.240 \\
-0.639 \\
-0.425\end{array}$ & $\begin{array}{l}-0.141 \\
-0.683 \\
-0.292 \\
-0.262\end{array}$ & $\begin{array}{r}0.034 \\
-0.501 \\
-0.372 \\
-0.150\end{array}$ & $\begin{array}{r}-0.379 \\
-0.455 \\
0.372 \\
-0.078\end{array}$ & $\begin{array}{r}-0.259 \\
0.074 \\
0.720 \\
0.537\end{array}$ \\
\hline
\end{tabular}

CN: chip noise; FR: tool fracture; SH: sharp tool; WR: worn tool.

Significant at $5 \%$ if entries are: $>0.229$ for $\mathrm{CN},>0.367$ for $\mathrm{FR}$, and $>0.22$ for $\mathrm{SH}$ and WR.

be estimated by available observations. This means that with 14 variables, a total of 98 parameters (the elements of a lower triangular covariance matrix for tool fracture state) must be estimated from a total of 406 data $(29 \times 14)$ points. This clearly reduces the number of degrees of freedom available for good estimation, resulting in poorer classification.

The results of Table 5 are not particularly good, especially in the case of detecting and discriminating between sharp tools and worn tools with up to $18 \%$ error in classification. Further examination of the data set 1 provides some explanations for these poor results. Table 6 gives the lag one serial correlations of the 14 variables selected for the discriminant analysis above. Similar serial correlations were present for the remaining 32 variables in each state. The serial correlations are significant for sharp and worn tool (this clearly is a violation of the underlying assumption of independence of observations in discriminant analysis). They are less strong for chip noise, and almost non-existent for tool fracture. The reason for lack of serial correlations between the observations for tool fracture in 
TABLE 5

Results of $Q D$ analysis of the 14 selected features listed in Table 1. Top entries are number of vectors classified into a population. Bold entries are percentage correct classification

\begin{tabular}{lcccc}
\hline & \multicolumn{4}{c}{ Predicted population } \\
\cline { 2 - 5 } \multicolumn{1}{c}{ True population } & Chip noise & Tool fracture & Sharp tool & Worn tool \\
\hline Chip noise & 74 & 0 & 0 & 0 \\
Tool fracture & 100 & 23 & 0 & 0 \\
Sharp tool & 6 & 79 & 66 & 14 \\
Worn tool & 0 & 0 & 82 & 67 \\
& 3 & 0 & 10 & 84 \\
\hline
\end{tabular}

TABLE 6

Lag 1 serial correlations of 14 selected variables (features) selected in the stepwise discriminant analysis

\begin{tabular}{|c|c|c|c|c|}
\hline $\begin{array}{l}\text { Variables } \\
\text { (features) }\end{array}$ & Chip noise & Tool fracture & Sharp tool & Worn tool \\
\hline 3 & $0 \cdot 155$ & 0.018 & 0.538 & 0.461 \\
\hline 4 & $0 \cdot 230$ & 0.146 & 0.473 & 0.570 \\
\hline 7 & $0 \cdot 137$ & -0.088 & 0.263 & $0 \cdot 314$ \\
\hline 8 & 0.015 & 0.053 & $0 \cdot 176$ & 0.286 \\
\hline 9 & -0.055 & -0.089 & $0 \cdot 223$ & 0.509 \\
\hline 10 & -0.251 & 0.028 & $0 \cdot 160$ & $0 \cdot 187$ \\
\hline 12 & -0.021 & -0.187 & $0 \cdot 198$ & $0 \cdot 255$ \\
\hline 15 & 0.259 & $-0 \cdot 193$ & 0.543 & 0.436 \\
\hline 16 & -0.088 & -0.097 & 0.561 & $0 \cdot 549$ \\
\hline 34 & $0 \cdot 329$ & $0 \cdot 362$ & 0.606 & 0.636 \\
\hline 38 & 0.444 & $0 \cdot 101$ & 0.647 & 0.606 \\
\hline 39 & 0.547 & -0.024 & 0.550 & 0.574 \\
\hline 44 & 0.516 & 0.095 & 0.414 & $0 \cdot 580$ \\
\hline 46 & 0.458 & -0.033 & 0.438 & 0.621 \\
\hline \multicolumn{5}{|l|}{ Significant at } \\
\hline $5 \%$ & 0.229 & 0.367 & 0.220 & 0.220 \\
\hline $1 \%$ & 0.298 & 0.471 & $0 \cdot 286$ & 0.286 \\
\hline
\end{tabular}

this study was the independent experiments which generated the 29 vectors (xs) of observations.

Another problem with the data is the lack of normality which was assumed for the above linear and quadratic discriminant function analyses. Figures 1-8 give histograms of eight features, two for each state. The shapes and the patterns of the histograms of the remaining variables in each state were similar to these eight histograms. For normally distributed observations, skewness and kurtosis must equal zero. Departure of these two measures from zero is sufficient indication of departure from normality. Nakanishi and 


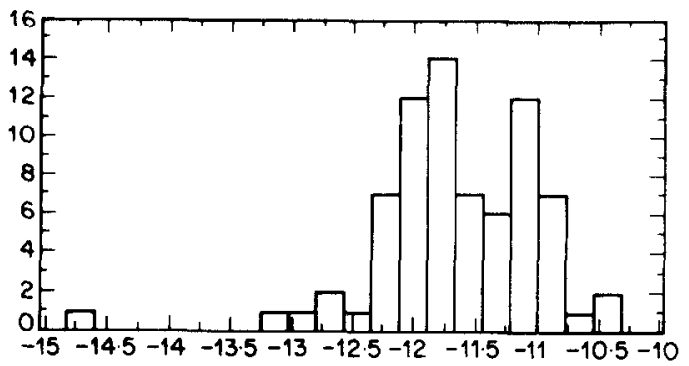

Figure 1. Histogram of feature 4 from chip noise. Skewness $=-1 \cdot 41$, kurtosis $=5 \cdot 40$.

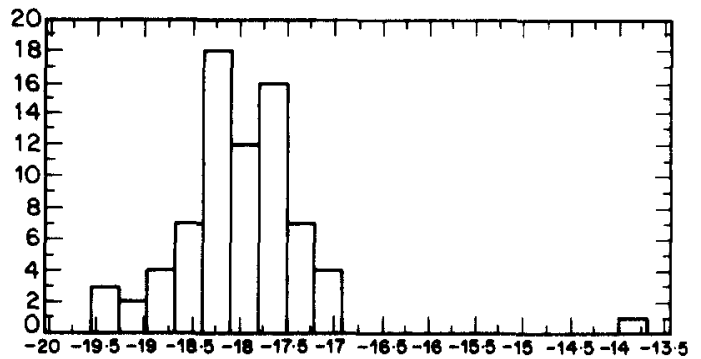

Figure 2. Histogram of feature 16 from chip noise. Skewness $=2 \cdot 16$, kurtosis $=12 \cdot 33$.

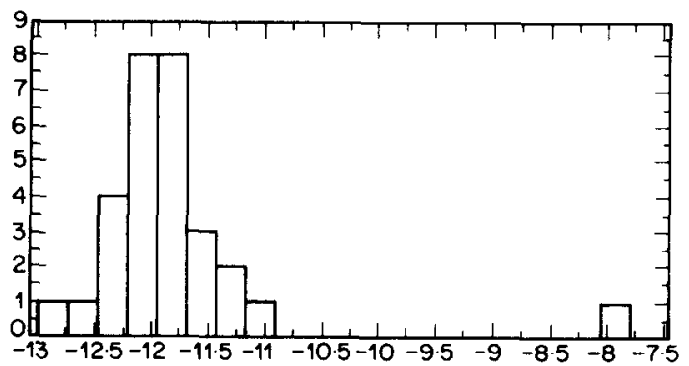

Figure 3. Histogram of feature 3 from tool fracture. Skewness $=3 \cdot 40$, kurtosis $=13 \cdot 70$.

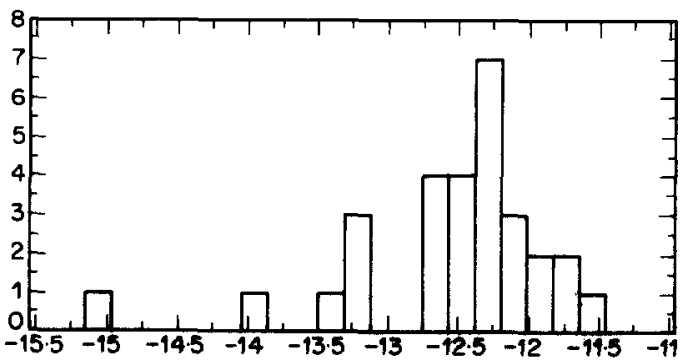

Figure 4. Histogram of feature 4 from tool fracture. Skewness $=-1 \cdot 75$, kurtosis $=3 \cdot 97$ 


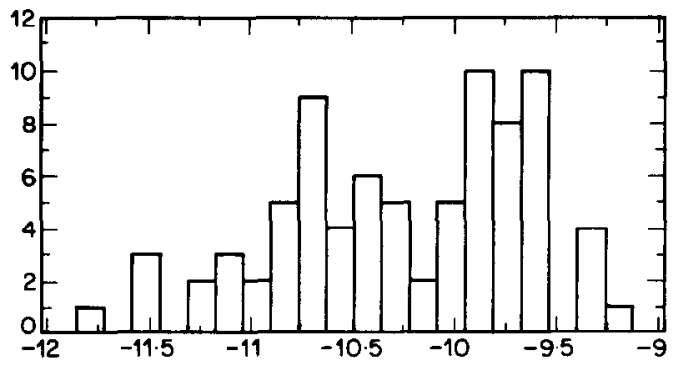

Figure 5. Histogram of feature 3 from sharp tool. Skewness $=-0 \cdot 42$, kurtosis $=-0 \cdot 58$.

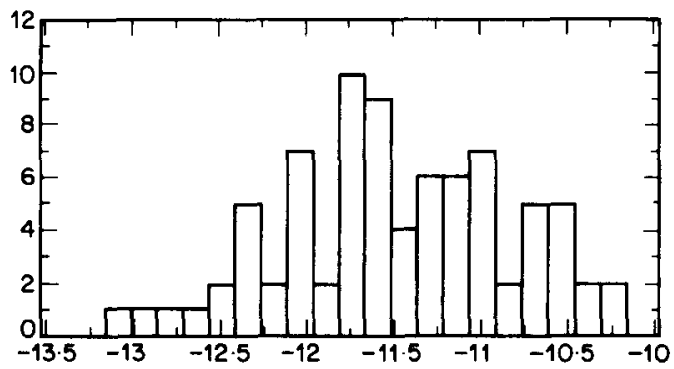

Figure 6. Histogram of feature 4 from sharp tool. Skewness $=-0 \cdot 21$, kurtosis $=-0 \cdot 43$.

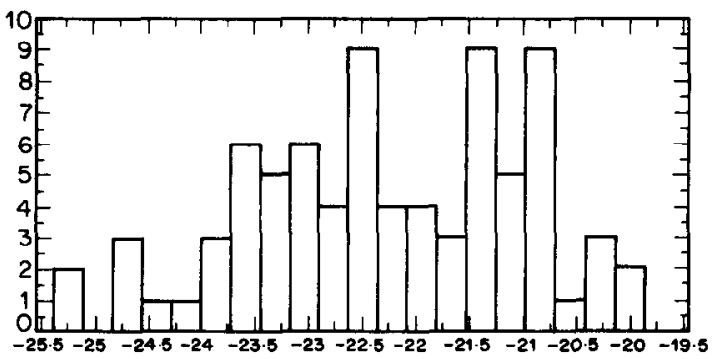

Figure 7. Histogram of feature 39 from worn tool. Skewness $=-0 \cdot 29$, kurtosis $=-0.67$.

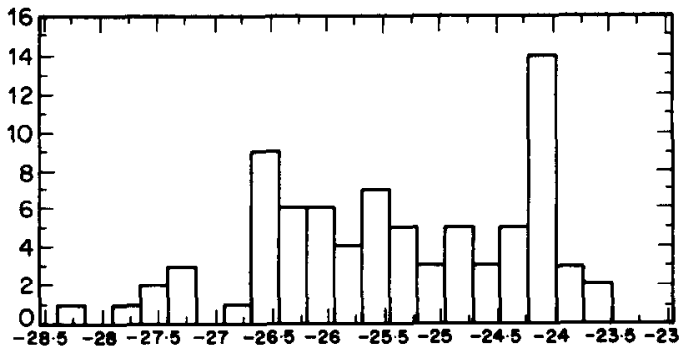

Figure 8. Histogram of feature 44 from worn tool. Skewness $=-0 \cdot 32$, kurtosis $=-0 \cdot 77$. 
Sato [22] pointed out that large skewness and kurtosis have important effects on the performance of the linear and quadratic discriminant functions.

The above results indicate that the standard linear or quadratic normal theory discriminant analysis do not produce optimum results for tool health monitoring using frequency domain AE signals. This may be due to the fact that the generated acoustic emission signals are mixed with various corrupting signals such as instrumentation noise, digitisation noise, vibration, etc. [23, 24]. We should therefore find a method of separating and isolating these signals to distinct components, and use those components for classification which represent the acoustic emission. The principal component analysis is a useful technique for separating data into distinct parts, since it performs an orthogonal transformation of the axes which characterise the data with each axis representing a distinct component. The concept of principal components was discussed in the preceding section. We applied this technique to our data and obtained the first six principal components for each of the three data sets.

Table 7 gives the cumulative percentage of total variance explained by the first six principal components of the data set 1 for each of the four states. Tables 8 and 9 give the corresponding cumulative percentages for data sets 2 and 3 respectively. Notice that for these two sets no data on the "tool fracture" state were available. It can be seen in the first column of Table 7 that the first principal component accounts for a large portion of the total variability in these data (between 49 and $83 \%$ ). Also, these six principal components, together, account for up to $91 \%$ of the total variance (sum of the elements along the diagonal of the variance covariance matrix). This means that instead of the 46 features we can use these six components, thereby reducing the problem size by 40 dimensions, but only lose up to $24 \%$ of the total variance. Furthermore, these components are orthogonal to each other (correlation between each pair is zero). This means that

\section{TABLE 7}

Cumulative percentage of variance explained by the first six principal components of the 46 variables in data set 1

\begin{tabular}{lcccccc}
\hline & \multicolumn{6}{c}{ Cumulative \% of variance explained, Set 1 } \\
\cline { 2 - 7 } \multicolumn{1}{c}{ State } & 1 & 2 & 3 & 4 & 5 & 6 \\
\hline Chip noise & $48 \cdot 7$ & $59 \cdot 7$ & $66 \cdot 3$ & $72 \cdot 1$ & $74 \cdot 4$ & $76 \cdot 4$ \\
Tool fracture & $52 \cdot 2$ & $63 \cdot 8$ & $72 \cdot 4$ & $76 \cdot 0$ & $79 \cdot 5$ & $82 \cdot 4$ \\
Sharp tool & $83 \cdot 1$ & $85 \cdot 7$ & $88 \cdot 0$ & $89 \cdot 2$ & $90 \cdot 0$ & $90 \cdot 7$ \\
Worn tool & $81 \cdot 2$ & $86 \cdot 8$ & $88 \cdot 4$ & $89 \cdot 5$ & $90 \cdot 3$ & $91 \cdot 0$ \\
\hline
\end{tabular}

TABLE 8

Cumulative percentage of variance explained by the first six principal components of the 46 variables in data set 2

\begin{tabular}{lcccccc}
\hline & \multicolumn{7}{c}{ Cumulative \% of variance explained, set 2 } \\
\cline { 2 - 7 } \multicolumn{1}{c}{ State } & 1 & 2 & 3 & 4 & 5 & 6 \\
\hline Chip noise & 62.4 & 72.2 & 76.5 & 79.2 & 81.5 & 83.6 \\
Sharp tool & 51.2 & 69.7 & 73.8 & 77.5 & 79.6 & 81.5 \\
Worn tool & 86.2 & $\mathbf{8 7 . 8}$ & 88.9 & 89.9 & 90.7 & 91.4 \\
\hline
\end{tabular}


TABLE 9

Cumulative percentage of variance explained by the first six principal components of the 46 variables in data set 3

\begin{tabular}{lcccccc}
\hline & \multicolumn{6}{c}{ Cumulative \% of variance explained, set 3} \\
\cline { 2 - 7 } \multicolumn{1}{c}{ State } & 1 & 2 & 3 & 4 & 5 & 6 \\
\hline Chip noise & $70 \cdot 1$ & $81 \cdot 5$ & $84 \cdot 7$ & $86 \cdot 2$ & $87 \cdot 5$ & $88 \cdot 6$ \\
Sharp tool & $84 \cdot 1$ & $87 \cdot 7$ & $90 \cdot 0$ & $90 \cdot 9$ & $91 \cdot 5$ & $92 \cdot 1$ \\
Worn tool & $83 \cdot 5$ & $87 \cdot 2$ & $88 \cdot 7$ & $90 \cdot 1$ & $90 \cdot 8$ & $91 \cdot 5$ \\
\hline
\end{tabular}

each component may represent a particular characteristic of the machining process. Similar results were found for the other data sets, as Tables 8 and 9 indicate.

Examination of these principal components revealed interesting results in terms of their descriptive statistics and their discriminatory powers. Table 10 gives the descriptive statistics of the six principal components for set 1 . Those of sets 2 and 3 are given in Tables 11 and 12 respectively. As Table 10 indicates, the first principal component for each state has about the same distribution (similar minimum, maximum, mean, standard deviation), but for the remaining principal components, these distributions seem to have

TABLE 10

Descriptive statistics of the six principal components for the four states of set 1

\begin{tabular}{|c|c|c|c|c|c|c|c|}
\hline \multirow[b]{2}{*}{ State } & \multirow{2}{*}{$\begin{array}{l}\text { Principal - } \\
\text { component }\end{array}$} & \multicolumn{6}{|c|}{ Descriptive statistics of the principal components, set 1} \\
\hline & & Min. & Max. & Mean & S.D. & Skewness & Kurtosis \\
\hline $\begin{array}{c}\text { Chip } \\
\text { noise } \\
(74)\end{array}$ & $\begin{array}{l}1 \\
2 \\
3 \\
4 \\
5 \\
6\end{array}$ & $\begin{array}{r}-125.9 \\
-10.5 \\
-49.5 \\
-5.5 \\
-5.0 \\
0.4\end{array}$ & $\begin{array}{r}-108.0 \\
3.1 \\
-40.9 \\
1.9 \\
-1.0 \\
3.8\end{array}$ & $\begin{array}{r}-118 \cdot 1 \\
0 \cdot 2 \\
-43 \cdot 5 \\
-2.5 \\
-2.9 \\
1.9\end{array}$ & $\begin{array}{l}3.7 \\
1.8 \\
1.4 \\
1.3 \\
0.8 \\
0.7\end{array}$ & $\begin{array}{r}0.17 \\
-3.45 \\
-1 \cdot 34 \\
0 \cdot 82 \\
0.05 \\
0.10\end{array}$ & $\begin{array}{c}-0.01 \\
17 \cdot 16 \\
4 \cdot 15 \\
2 \cdot 16 \\
-0.27 \\
-0.23\end{array}$ \\
\hline $\begin{array}{c}\text { Tool } \\
\text { fracture } \\
(29)\end{array}$ & $\begin{array}{l}1 \\
2 \\
3 \\
4 \\
5 \\
6\end{array}$ & $\begin{array}{r}-127.6 \\
-1.1 \\
-6.0 \\
-3.5 \\
8.9 \\
6.6\end{array}$ & $\begin{array}{r}-105.6 \\
10.0 \\
0.6 \\
0.2 \\
12.6 \\
9.9\end{array}$ & $\begin{array}{r}-119.7 \\
4 \cdot 2 \\
-1.4 \\
-1 \cdot 6 \\
11 \cdot 0 \\
8.2\end{array}$ & $\begin{array}{l}3.6 \\
1.7 \\
1.4 \\
0.9 \\
0.9 \\
0.8\end{array}$ & $\begin{array}{r}1.78 \\
0.34 \\
-1.88 \\
-0.07 \\
-0.21 \\
-0.07\end{array}$ & $\begin{array}{r}7 \cdot 37 \\
6 \cdot 30 \\
3 \cdot 77 \\
-0 \cdot 51 \\
-0 \cdot 40 \\
-0 \cdot 49\end{array}$ \\
\hline $\begin{array}{l}\text { Sharp } \\
\text { tool } \\
(80)\end{array}$ & $\begin{array}{l}1 \\
2 \\
3 \\
4 \\
5 \\
6\end{array}$ & $\begin{array}{r}-123 \cdot 1 \\
20 \cdot 0 \\
16 \cdot 4 \\
-34 \cdot 4 \\
-16 \cdot 6 \\
-5 \cdot 4\end{array}$ & $\begin{array}{r}-99.9 \\
26.0 \\
21.5 \\
-30.5 \\
1.8 \\
-2.9\end{array}$ & $\begin{array}{r}-112 \cdot 5 \\
22 \cdot 7 \\
19 \cdot 0 \\
-32 \cdot 9 \\
0.5 \\
-4 \cdot 2\end{array}$ & $\begin{array}{l}6.2 \\
1.1 \\
1.0 \\
0.7 \\
0.6 \\
0.6\end{array}$ & $\begin{array}{r}-0.12 \\
0.39 \\
0.09 \\
0.36 \\
-0.38 \\
-0.04\end{array}$ & $\begin{array}{r}-1 \cdot 18 \\
0 \cdot 14 \\
-0 \cdot 28 \\
0 \cdot 64 \\
0 \cdot 56 \\
-0 \cdot 35\end{array}$ \\
\hline $\begin{array}{l}\text { Worn } \\
\text { tool } \\
(80)\end{array}$ & $\begin{array}{l}1 \\
2 \\
3 \\
4 \\
5 \\
6\end{array}$ & $\begin{array}{r}-126.9 \\
-25 \cdot 7 \\
41.6 \\
-1.9 \\
-4 \cdot 0 \\
-5 \cdot 1\end{array}$ & $\begin{array}{r}-100 \cdot 8 \\
-17 \cdot 1 \\
45 \cdot 6 \\
2 \cdot 7 \\
-0.7 \\
-1 \cdot 8\end{array}$ & $\begin{array}{r}-112 \cdot 2 \\
-22 \cdot 5 \\
44 \cdot 0 \\
-0 \cdot 3 \\
-2 \cdot 4 \\
-3 \cdot 1\end{array}$ & $\begin{array}{l}6.3 \\
6.7 \\
0.9 \\
0 \cdot 8 \\
0.6 \\
0.6\end{array}$ & $\begin{array}{r}-0.15 \\
0.30 \\
-0.61 \\
0.60 \\
0.26 \\
-0.32\end{array}$ & $\begin{array}{r}-0.92 \\
0.18 \\
0.32 \\
1.71 \\
0.17 \\
0.48\end{array}$ \\
\hline
\end{tabular}

Sample size in parentheses. 
TABLE 11

Descriptive statistic of the six principal components for the three states of set 2

\begin{tabular}{|c|c|c|c|c|c|c|c|}
\hline \multirow[b]{2}{*}{ State } & \multirow{2}{*}{$\begin{array}{l}\text { Principal } \\
\text { component }\end{array}$} & \multicolumn{6}{|c|}{ Descriptive statistics of the principal components, set 2} \\
\hline & & Min. & Max. & Mean & S.D. & Skewness & Kurtosis \\
\hline Chip & 1 & $-122 \cdot 2$ & $-102 \cdot 7$ & $-113 \cdot 7$ & $4 \cdot 4$ & 0.43 & $-0 \cdot 10$ \\
\hline noise & 2 & $-34 \cdot 7$ & $-25 \cdot 2$ & $-31 \cdot 2$ & 1.7 & $1 \cdot 62$ & $4 \cdot 16$ \\
\hline \multirow[t]{4}{*}{$(40)$} & 3 & $-43 \cdot 6$ & $-37 \cdot 0$ & $-40 \cdot 3$ & $1 \cdot 2$ & $-0 \cdot 12$ & $1 \cdot 40$ \\
\hline & 4 & $1 \cdot 6$ & $5 \cdot 7$ & $3 \cdot 0$ & 0.9 & 0.88 & 0.45 \\
\hline & 5 & $1 \cdot 0$ & $5 \cdot 5$ & $3 \cdot 3$ & 0.8 & $0 \cdot 21$ & $1 \cdot 2$ \\
\hline & 6 & $-16 \cdot 3$ & $-12 \cdot 7$ & $-14 \cdot 0$ & $0 \cdot 8$ & $-0 \cdot 62$ & $0 \cdot 54$ \\
\hline Sharp & 1 & $-109 \cdot 3$ & $-94 \cdot 7$ & $-101 \cdot 8$ & $3 \cdot 2$ & $-0 \cdot 31$ & 0.43 \\
\hline tool & 2 & $-3 \cdot 8$ & $10 \cdot 5$ & 0.4 & 1.9 & $3 \cdot 32$ & $16 \cdot 7$ \\
\hline \multirow[t]{4}{*}{$(40)$} & 3 & $-39 \cdot 0$ & $-34 \cdot 2$ & $-36 \cdot 3$ & 0.9 & -0.53 & 0.96 \\
\hline & 4 & -10.8 & -6.6 & $-8 \cdot 2$ & 0.9 & -0.46 & 0.42 \\
\hline & 5 & $-1 \cdot 5$ & $1 \cdot 2$ & -0.4 & 0.6 & 0.50 & $-0 \cdot 19$ \\
\hline & 6 & $-8 \cdot 6$ & $-5 \cdot 8$ & $-7 \cdot 3$ & 0.6 & 0.09 & -0.42 \\
\hline Worn & 1 & $-120 \cdot 4$ & $-95 \cdot 4$ & $-107 \cdot 8$ & $6 \cdot 5$ & -0.54 & -0.88 \\
\hline tool & 2 & $-13 \cdot 2$ & $-9 \cdot 3$ & $-11 \cdot 3$ & 0.9 & -0.23 & $-0 \cdot 30$ \\
\hline \multirow[t]{4}{*}{$(60)$} & 3 & $-34 \cdot 5$ & -30.9 & $-32 \cdot 9$ & 0.7 & 0.44 & 0.06 \\
\hline & 4 & $-26 \cdot 9$ & $-24 \cdot 0$ & $-25 \cdot 5$ & 0.7 & $0 \cdot 22$ & $-0 \cdot 51$ \\
\hline & 5 & $-3 \cdot 9$ & $-1 \cdot 0$ & $-2 \cdot 4$ & 0.6 & $-0 \cdot 16$ & $-0 \cdot 13$ \\
\hline & 6 & $25 \cdot 0$ & $27 \cdot 5$ & $26 \cdot 3$ & 0.6 & -0.02 & -0.63 \\
\hline
\end{tabular}

Sample size in parentheses.

TABLE 12

Descriptive statistics of the six principal components for the three states of set 3

\begin{tabular}{|c|c|c|c|c|c|c|c|}
\hline \multirow[b]{2}{*}{ State } & \multirow{2}{*}{$\begin{array}{l}\text { Principal } \\
\text { component }\end{array}$} & \multicolumn{6}{|c|}{ Descriptive statistics of the principal components, set 3} \\
\hline & & Min. & Max. & Mean & S.D. & Skewness & Kurtosis \\
\hline \multirow{6}{*}{$\begin{array}{l}\text { Chip } \\
\text { noise } \\
(70)\end{array}$} & 1 & $-131 \cdot 2$ & $-108 \cdot 0$ & $-121 \cdot 3$ & $5 \cdot 8$ & 0.41 & -0.71 \\
\hline & 2 & $-38 \cdot 4$ & $-22 \cdot 9$ & $-28 \cdot 1$ & $2 \cdot 4$ & $-1 \cdot 12$ & 3.98 \\
\hline & 3 & $-50 \cdot 2$ & $-41 \cdot 2$ & $-43 \cdot 4$ & $1 \cdot 2$ & $-2 \cdot 44$ & $11 \cdot 75$ \\
\hline & 4 & $3 \cdot 6$ & $10 \cdot 0$ & $8 \cdot 6$ & $0 \cdot 8$ & $-3 \cdot 02$ & $16 \cdot 13$ \\
\hline & 5 & $13 \cdot 5$ & $-8 \cdot 0$ & $-10 \cdot 4$ & $0 \cdot 8$ & $-0 \cdot 32$ & $2 \cdot 79$ \\
\hline & 6 & $-0 \cdot 9$ & $2 \cdot 8$ & $1 \cdot 0$ & $0 \cdot 7$ & $-0 \cdot 28$ & $0 \cdot 39$ \\
\hline \multirow{6}{*}{$\begin{array}{c}\text { Sharp } \\
\text { tool } \\
(80)\end{array}$} & 1 & $-129 \cdot 7$ & $-99 \cdot 3$ & $-113 \cdot 1$ & $7 \cdot 2$ & 0.23 & -0.80 \\
\hline & 2 & $13 \cdot 9$ & $20 \cdot 8$ & $17 \cdot 4$ & 1.5 & $0 \cdot 32$ & $-0 \cdot 27$ \\
\hline & 3 & $-31 \cdot 9$ & $-25 \cdot 8$ & $-29 \cdot 7$ & $1 \cdot 2$ & 0.67 & 1.23 \\
\hline & 4 & $-26 \cdot 4$ & $-22 \cdot 8$ & $-24 \cdot 3$ & $0 \cdot 7$ & 0.62 & 0.27 \\
\hline & 5 & $-10 \cdot 7$ & $-7 \cdot 4$ & $-8 \cdot 9$ & 0.6 & $-0 \cdot 30$ & 0.03 \\
\hline & 6 & $-1 \cdot 6$ & $1 \cdot 5$ & $-0 \cdot 3$ & 0.6 & 0.28 & 0.37 \\
\hline \multirow{6}{*}{$\begin{array}{l}\text { Worn } \\
\text { tool } \\
(80)\end{array}$} & 1 & $-124 \cdot 8$ & $-94 \cdot 0$ & $-107 \cdot 9$ & 6.9 & -0.48 & -0.50 \\
\hline & 2 & $-28 \cdot 1$ & $-18 \cdot 5$ & $-21 \cdot 4$ & $1 \cdot 4$ & $-1 \cdot 19$ & $4 \cdot 31$ \\
\hline & 3 & $-50 \cdot 5$ & $-45 \cdot 6$ & $-47 \cdot 1$ & 0.9 & $-1 \cdot 20$ & 1.96 \\
\hline & 4 & $7 \cdot 3$ & $12 \cdot 0$ & $12 \cdot 0$ & 0.9 & $-0 \cdot 30$ & $0 \cdot 10$ \\
\hline & 5 & $6 \cdot 2$ & $-2 \cdot 7$ & $-4 \cdot 3$ & 0.6 & 0.01 & 0.73 \\
\hline & 6 & 0.6 & $3 \cdot 8$ & $2 \cdot 5$ & 0.6 & -0.24 & 0.07 \\
\hline
\end{tabular}

Sample size in parentheses. 
completely different locations (means) in each state, as well as other differences. More importantly, by comparing Tables $10-12$, the distribution of the first principal component seems to be the same, irrespective of the cutting conditions of the process. This means that the first principal component, despite its importance in terms of amount of variance it explains, has no discriminatory power. It also indicates that the first principal component is describing a particular characteristic of the system which is present irrespective of the condition of the cutting tool or the cutting conditions of the process.

Figures 9-11 give three plots of $\alpha_{i j}$ vs. j (one from each data set, 1, 2, and 3), for $j=1,2, \ldots, 46$, where $\alpha_{1}^{\prime}=\left(\alpha_{11}, \alpha_{12}, \ldots, \alpha_{146}\right)$ are optimally calculated weights which maximise the variance of the first principal component $Y_{1}$, and

$$
Y_{1}=\sum_{j=1}^{46} \alpha_{1 k} X_{j}
$$

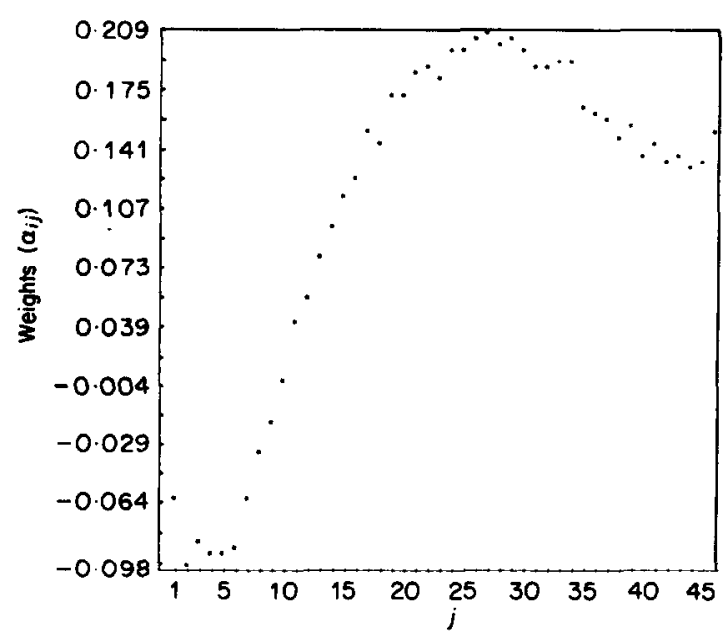

Figure 9. $\alpha_{1 j}$ vs. $j$ for the sharp tool data of Set $1 . X=\left(X_{1}, X_{2}, \ldots, X_{46}\right) \equiv 46$-dimensional vector of features. $Y_{1}=\sum_{j=1}^{46} \alpha_{1 j} X_{j} \equiv$ first principal component of the 46 features, where $\sum_{j=1}^{46} \alpha_{1 j}^{2}=1$.

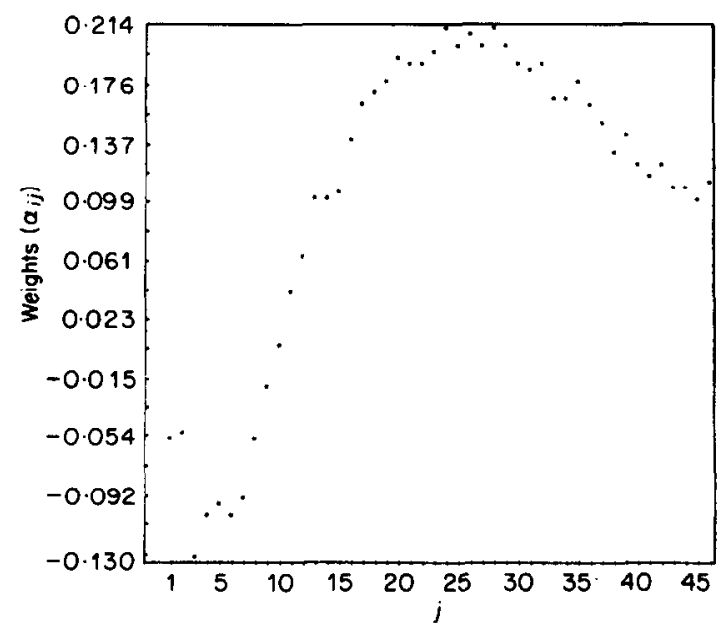

Figure 10. $\alpha_{1 j}$ vs. $j$ for the worn tool data of set $2 . X=\left(X_{1}, X_{2}, \ldots, X_{46}\right)=46$-dimensional vector of features. $Y_{1}=\sum_{i=1}^{46} \alpha_{1 j} X_{j}=$ first principal component of the 46 features, where $\sum_{j-1}^{46} \alpha_{1 j}^{2}=1$. 


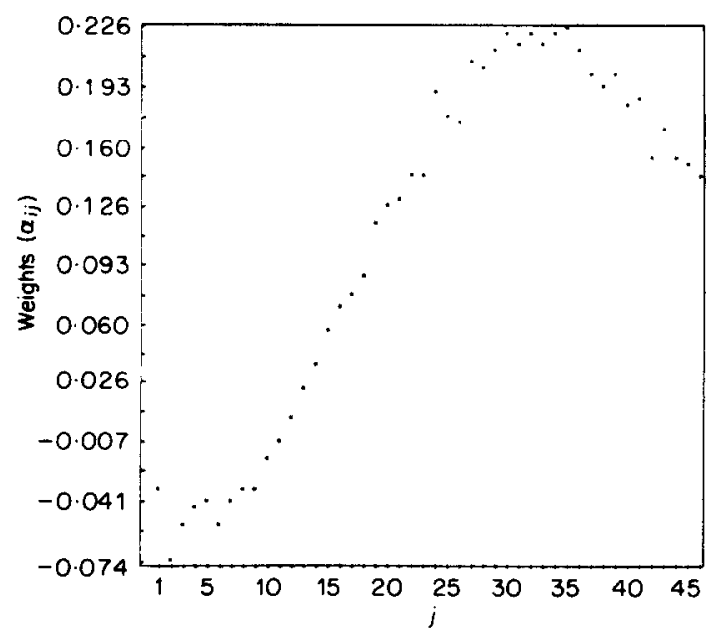

Figure 11. $\alpha_{1}$, vs. $j$ for the chip noise data of set 3. $X=\left(X_{1}, X_{2}, \ldots, X_{46}\right)=46$ dimensional vector of features. $Y_{1}=\sum_{j=1}^{46} \alpha_{1 j} X_{j} \equiv$ first principal component of the 46 features, where $\sum_{j=1}^{46} \alpha_{1 j}^{2}=1$.

(no apparent pattern was detected for any other $\alpha_{k j}$ vs. $j$ for $k=2,3, \ldots, 6$ ). As these figures indicate, the weights are very small (less than $0 \cdot 1$ ) for small values of $j$. Now since $j$ represents the features at different frequencies, this means that the features at frequencies less than $400 \mathrm{kHz}$ or so contribute very little to the first principal component. This contribution seems to be largest in the frequency range of $400-800 \mathrm{kHz}$. Therefore, the first principal component must represent a particular characteristic of the system which is unaffected by the cutting conditions or the state of the cutting tool (e.g., electronics noise, digitisation noise, instrumentation noise, etc.). This is further supported by the fact that, discarding this component and performing linear discriminant analysis on the next five components, produce $100 \%$ correct classification for all three data sets. Table 13 gives the results of this analysis for data set 1 . A comparison of this table with those of 1 and 2 reveals the improvement in the results obtained. It must be pointed out that in this paper we have resubstituted the same data points that were used to obtain the discriminant functions for validation (calculation of percentage correct classification). This is because we believe that classification techniques should be reliable enough to

TABLE 13

Number of vectors classified into a population. Bold entries are percentage of correct classification

\begin{tabular}{|c|c|c|c|c|}
\hline \multirow[b]{2}{*}{ True population } & \multicolumn{4}{|c|}{ Classified population } \\
\hline & Chip noise & Tool fracture & Sharp tool & Worn tool \\
\hline Chip noise & $\begin{array}{r}74 \\
100\end{array}$ & 0 & 0 & 0 \\
\hline Tool fracture & 0 & $\begin{array}{r}29 \\
100\end{array}$ & 0 & 0 \\
\hline Sharp tool & 0 & 0 & $\begin{array}{r}80 \\
100\end{array}$ & 0 \\
\hline Worn tool & 0 & 0 & 0 & $\begin{array}{r}80 \\
100\end{array}$ \\
\hline
\end{tabular}


classify correctly the same data points that were used to develop them. Also, since we did not have large data sets, cross validation of our results was not possible. The results may therefore appear optimistic. However, we believe that our results will be repeated with fresh data since the distribution of the principal components are very different for each state.

A further examination of Table 10 reveals an interesting result. Consider, for example, the third principal component. The range of numbers in this component are from $-49 \cdot 5$ to -40.9 for chip noise, -6 to 0.6 for tool fracture, 16.4 to 21.5 for a sharp tool, and 41.6 to 45.6 for a worn tool. Clearly, there is no intersection between these four ranges of numbers. Therefore, it is possible to use only this component to classify signals into one of the four states by a simple inspection. It must, however, be noted that this inspection method does not always produce such good results. This is evident in Table 12 where no unique component has the characteristics of the third component in Table 10.

\section{CONCLUSIONS}

The use of $\mathrm{AE}$ methodology as a sensing technique for monitoring the condition of a cutting tool in metal cutting is examined in the context of statistical pattern recognition (linear or quadratic discriminant functions), as a tool for signal decomposition. It was found that the spectral power of acoustic emission signals are cross and serially correlated, and that they do not necessarily satisfy the required normality assumption. Departure from these major assumptions caused the classifier's performance to be less than optimum.

The principal component analysis of data in each state indicated that the spectral power of acoustic emission signals are contaminated by noise in the system. This noise was represented by the first principal component which had no discriminatory power. The amount of noise in the system was found to be maximum in the frequency range of 400 to $800 \mathrm{kHz}$. Separating the noise forms AE produced components with strong discriminatory power, so much so that only a few principal components produced $100 \%$ correct classification (under resubstitution of data). These results were particularly promising since they were repeated under three different cutting conditions. We suggest that further experiments under various cutting conditions can shed more light on the universality of these results.

\section{ACKNOWLEDGEMENT}

We would like to thank Dr Erdal Emel for providing the data used in this paper. The support of this research by the National Science Foundation under Grant Number DMC-8607198 and by the University of Michigan Industrial Consortium on Diagnostic Sensing and Control for Metal Cutting, as well as the Industrial Technology Institute, is greatly appreciated.

\section{REFERENCES}

1. Y. KAKINO 1980 ASM Proceedings of an International Conference on Cutting Tool Materials, In-process detection of tool breakage by monitoring acoustic emission. pp. 25-39.

2. I. INASAKI and S. YONETSU 1981 Proceedings of the International Machine Tool Design and Research Conference, 22, pp. 261-268. In-process detection of cutting tool damage by acoustic emission measurement.

3. E. KANNATEY-ASIBU, JR and D. A. DoRnfEld 1982 Wear 76. A study of tool wear using statistical analysis of metal cutting acoustic emission. 
4. E. N. DIEI and D. A. DORNFELD 1985 Sensors and Controls for Manufacturing (E. KannateyAsibu, Jr, A. G. Ulsoy and R. Komanduri, editors pp. 33-39. ASME Publication, PED-Vol. 18. A model of tool fracture generated acoustic emission during machining.

5. E. KANNATEY-ASIBU JR and D. A. DORNFELD 1981 Journal of Engineering for Industry, 103, 330-340. Quantitative relationships for acoustic emission from orthogonal metal cutting.

6. E. Kannetay-Asibu, JR 1982 Proceedings of the Tenth NAMRC, pp. 487-492. On the application of the pattern recognition method to manufacturing process monitoring.

7. D. A. DORNFELD and C. S. PAN 1985 Proceedings of the Thirteenth NAMRC, Berkely, CA, pp. 299-303. Determination of chip forming states using linear discriminant function technique with acoustic emission.

8. E. Kannatey-Asibu, JR and E. EMel 1987 Mechanical Systems and Signals Processing 1, 333-347. Linear discriminant function analysis of acoustic emission signals for cutting tool monitoring.

9. E. EMEL and E. KANNATEY-ASIBU, JR 1988 ASME Journal of Engineering Industry 110, 137-145. Tool failure monitoring in turning by pattern recognition analysis of AE signals.

10. R. A. FISHER 1936 Annals of Eugenics 7, 179-188. The use of multiple measurements in toxonomic problems.

11. C. A. B. SMIth 1947 Annals of Eugenics 13, 272-282. Some examples of discrimination.

12. D. F. MORRISON 1967 Multivariate Statistical Method. New York: McGraw-Hill.

13. S. J. PRess 1972 Applied Multivariate Analysis, New York: Holt, Rinehart and Winston.

14. K. FUKUNAGA 1972 Introduction to Statistical Pattern Recognition, New York: Academic Press.

15. A. A. AfIFI and S. P. AZEN 1972 Statistical Analysis. A Computer Oriented Approach. New York: Academic Press.

16. R. I. JENNRICH 1977 Statistical Method for Digital Computers, Vol. III. New York: John Wiley. Stepwise discriminant analysis.

17. T. W. ANDERSON 1984 An Introduction to Multivariate Statistical Analysis, Second Edition. New York: John Wiley.

18. C. K. BAYNE and J. J. BeAUCHAMP 1984 Communication in Statistics-Simulation and Computation 13(5), 669-682. Misclassification probabilities for second-order discriminant functions used to classify bivariate normal populations.

19. J. J. DAUDIN 1986 Biometrics 42, pp. 473-481. Selection of variables in mixed variable discriminant analysis.

20. N. R. DRAPER and H. SMith 1981 Applied Regression Analysis, Second Edition. New York: John Wiley.

21. D. H. FOLEY 1972 IEEE Transactions on Information Theory IT-18, 618-626. Consideration of sample and feature size.

22. H. NAKANISHI and Y. SATO 1985 Communication in Statistics-Theory and Methods 14(5), 1181-1200. The performance of the linear and quadratic discriminant functions of three types of non-normal distributions.

23. L. J. Graham and G. A. Alers 1975 Monitoring Structural Integrity by Acoustic Emission, ASTM STP 571, pp. 11-39. Acoustic emission in frequency domain.

24. P. HoRvATH and F. J. COOK 1981 Quantitative Non-destructive Evaluation 1, 463-473. Establishing signal processing and pattern recognition techniques for inflight discrimination between crack-growth acoustic emission and other acoustic waveforms.

\section{APPENDIX A. STEPWISE DISCRIMINANT ANALYSIS}

Here we describe the stepwise method used for feature selection in our analysis of data. This method is described by Afifi and Azen [15].

Suppose $\mathbf{Y} \sim N\left(\boldsymbol{\mu}_{Y}, \boldsymbol{\Sigma}\right)$, where $\boldsymbol{\mu}_{Y}$ is the $k$-dimensional vector of means, and $\boldsymbol{\Sigma}$ is the $k \times k$ variance-covariance matrix. Partition $\mathbf{Y}, \boldsymbol{\mu}_{Y}$, and $\mathbf{\Sigma}$ as:

$$
\mathbf{Y}=\left(\begin{array}{c}
\mathbf{Z} \\
\mathrm{T}
\end{array}\right), \quad \boldsymbol{\mu}_{Y}=\left(\begin{array}{c}
\boldsymbol{\mu}_{z} \\
\boldsymbol{\mu}_{T}
\end{array}\right), \quad \Sigma=\left(\begin{array}{cc}
\Sigma_{11} & \Sigma_{12} \\
\Sigma_{21} & \Sigma_{22}
\end{array}\right) .
$$

Where Y: $k \times 1, \mathbf{Z}: u \times 1, \mathbf{T}: v \times 1, \Sigma_{11}: u \times u, \Sigma_{22}: v \times v, \Sigma_{12}: u \times v, \Sigma_{21}: v \times u$, and $u+v=k$. Now, if $\Sigma_{11}>0$, and $\Sigma_{22}>0$, then $Z \sim N\left(\mu_{Z}, \Sigma_{11}\right)$, and $T \sim N\left(\mu_{T}, \Sigma_{22}\right)$. It follows that the conditional distribution of $\mathbf{Z}$ given $\mathbf{T}=\mathbf{t}$ is also multivariate normal with mean vector 
a linear function of $t$, and variance-covariance matrix independent of $t$; that is

$$
(Z \mid \mathbf{T}=\mathbf{t}) \sim N\left[\boldsymbol{\mu}_{Z}+\Sigma_{12} \Sigma_{22}^{-1}\left(\mathbf{t}-\boldsymbol{\mu}_{T}\right), \Sigma_{11.2}\right]
$$

where $\Sigma_{11 \cdot 2}=\Sigma_{11}-\Sigma_{12} \Sigma_{22}^{-1} \Sigma_{21}$.

Let $\mathbf{X}_{j}^{i}=\left(X_{j 1}^{i}, X_{j 2}^{i}, \ldots, X_{j k}^{i}\right)^{\prime}$ be the $j$-th random vector from population $i$, and $\mu^{i}=$ $\left(\mu_{1}^{i}, \mu_{2}^{i}, \ldots, \mu_{k}^{i}\right)^{\prime}$ be the mean vector of population $i$, (for $\left.i=1,2, \ldots, s\right)$. Let $V_{r}$ denote the $r$-th feature; the procedure for stepwise discrimination is as follows.

First the $F$ to enter along with its degrees of freedom is computed for each $V_{r}$, $r=1,2, \ldots, k$. This $F$ to enter is the one-way analysis of variance $F$ statistic for testing the null hypothesis $H_{0}: \mu_{r}^{1}=\mu_{r}^{2}=, \ldots, \mu_{r}^{s}$. That is,

$$
F=\frac{\frac{\sum_{i=1}^{s} n^{i}\left(\bar{X}_{r}^{i}-\bar{X}_{r}\right)^{2}}{(s-1)}}{\frac{\sum_{i=1}^{s} \sum_{j=1}^{n^{i}}\left(X_{j r}^{i}-\bar{X}_{r}^{i}\right)^{2}}{(n-s)}} \quad(r=1,2, \ldots, k) .
$$

where $n^{i}$ is the sample size for state $i$,

$$
n=\sum_{i=1}^{s} n^{i}
$$

and $\bar{X}_{r}^{i}$ is the $r$-th sample estimate of $\mu_{r}^{i}$, and $\bar{X}_{r}$ is the $r$-th sample estimate of feature mean, $\mu_{r}$ say. Now if all $F$ to enter $\left(F_{r}\right)$ are less than a prescribed inclusion level, called the $F$ to include (the $F$ value corresponding to $\alpha$ level of significance), the process terminates and we conclude that no feature significantly discriminates between the populations. Otherwise the feature $V_{r 1}$ having the largest $F$ to enter is selected as the first feature. We then use (A.2) to find the conditional distribution of the remaining $k-1$ features conditioned on the feature selected, and use them to calculate the $F$ to enter and its degrees of freedom for each feature not entered. This tests the null hypothesis $H_{0}: \mu_{r \cdot r_{1}}^{1}=\cdots=\mu_{r \cdot r_{1}}^{s}$, where $\mu_{r r_{1}}^{i}$ is the mean of the conditional distribution in population $i$ of $V_{r}$ given $V_{r_{1}}, i=1,2, \ldots, s, r=1,2, \ldots, k, r \neq r_{1}$. If all the $F$ to enter values of the remaining features are less than $F$ to include, then we stop the process and conclude that only $V_{r_{1}}$ discriminates, between the populations. Otherwise the feature $V_{r_{2}}$ with the maximum value of $F$ to enter is selected. Note that in the subsequent calculation of $F$ statistics for any feature, we must take into account the fact that although the distributions of $V_{r} s$ remain normal, the parametrisation changes because these distribution are now conditional. Therefore a different expression from (A.3) must be used to obtain these $F$ values.

Now, we use (A.2) again, to obtain the conditional distributions of $V_{r_{1}}$ given $V_{r_{2}}$, and $V_{r_{2}}$ given $V_{r_{1}}$, as well as the conditional distributions of all the features not entered. Then we calculate two $F$ to remove values and their degrees of freedom for $V_{r_{1}}$ and $V_{r_{2}}$. These test null hypothesis $H_{0}: \mu_{r_{1} \cdot r_{2}}^{1}=\cdots=\mu_{r_{1} \cdot r_{2}}^{s}$ and $H_{0}: \mu_{r_{2} \cdot r_{1}}^{1}=\cdots=\mu_{r_{2} \cdot r_{1}}^{s}$, respectively. If either of the $F$ to remove values are less than $F$ to include value, then the feature with the smallest $F$ to remove value is removed from the list and added to the excluded features. Otherwise the $F$ to enter and its degree of freedom for each feature not entered are calculated. This tests the hypothesis $H_{0}: \mu_{r r_{1} r_{2}}^{1}=\cdots=\mu_{r \cdot r_{1} r_{2}}^{s}$, where $\mu_{r \cdot r_{1} r_{2}}^{i}$ is the mean of the conditional distribution in population $i$ of $V_{r}$ given $V_{r_{1}}$ and $V_{r_{2}}, i=1,2, \ldots, s$, $r=1,2, \ldots, k, r \neq r_{1}$ or $r_{2}$. If all $F$ to enter values are less than the $F$ to include value, 
then the process stops, otherwise the feature with the largest $F$ to enter is selected as the third feature. We continue this process until either the inclusion and the exclusion tests fail, or all the features are included.

The procedure described above is the forward selection discriminant function. The backward elimination procedure follows similar steps except that in that case we start with all the features included and try to exclude one feature at a time.

\section{APPENDIX B. NOMENCLATURE}

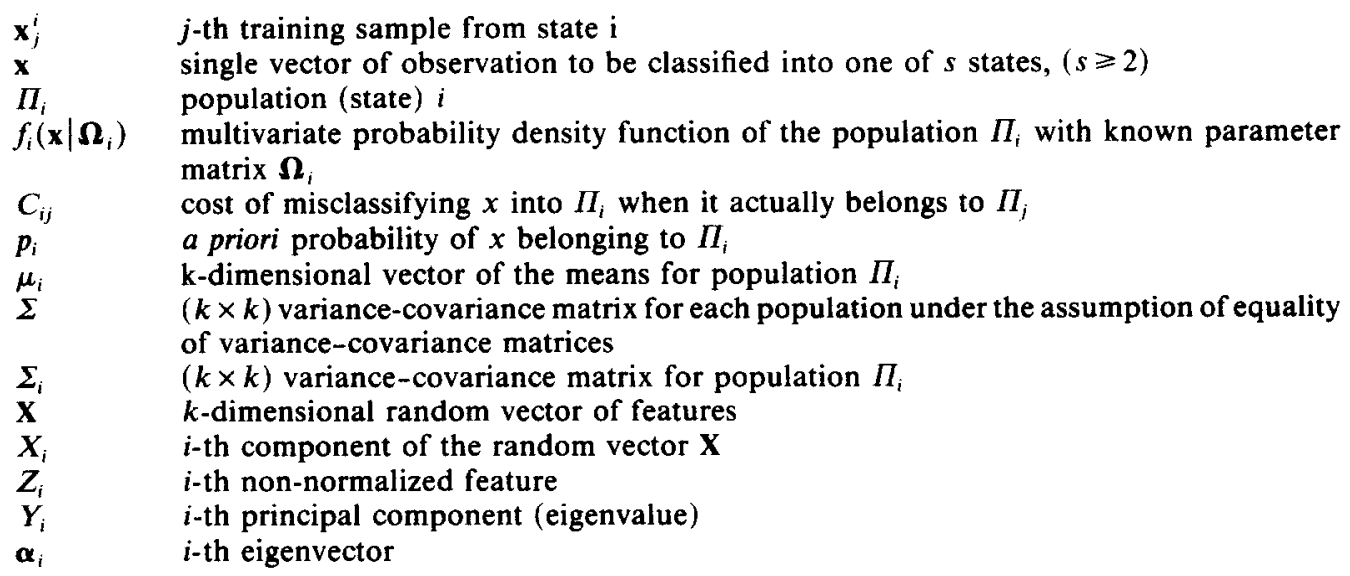

